Portland State University

PDXScholar

Physics Faculty Publications and Presentations

Physics

9-21-2019

\title{
Using a Local Positioning System to Track 2D Motion
}

\author{
Paul R. DeStefano \\ Portland State University, des3@pdx.edu \\ Cora Siebert \\ Portland State University, cora@pdx.edu \\ Ralf Widenhorn \\ Portland State University, ralfwidenhorn@pdx.edu
}

Follow this and additional works at: https://pdxscholar.library.pdx.edu/phy_fac

Part of the Physics Commons

Let us know how access to this document benefits you.

\section{Citation Details}

DeStefano, P. R., Siebert, C., \& Widenhorn, R. (2019). Using a local positioning system to track 2D motion. The Physics Teacher, 57(7), 508-509.

This Article is brought to you for free and open access. It has been accepted for inclusion in Physics Faculty Publications and Presentations by an authorized administrator of PDXScholar. Please contact us if we can make this document more accessible: pdxscholar@pdx.edu. 


\section{Using a local positioning system to track 2D motion}

Paul R. DeStefano, Cora Siebert, and Ralf Widenhorn

Citation: The Physics Teacher 57, 508 (2019); doi: 10.1119/1.5126843

View online: https://doi.org/10.1119/1.5126843

View Table of Contents: https://aapt.scitation.org/toc/pte/57/7

Published by the American Association of Physics Teachers

\section{ARTICLES YOU MAY BE INTERESTED IN}

A tennis ball accelerometer model

The Physics Teacher 57, 510 (2019); https://doi.org/10.1119/1.5126844

Rectilinear movement and functions through the analysis of videos with Tracker

The Physics Teacher 57, 506 (2019); https://doi.org/10.1119/1.5126842

Determination of the orbital inclination of the ISS with a smartphone

The Physics Teacher 57, 502 (2019); https://doi.org/10.1119/1.5126840

Body Composition Analysis: The Physics of Measuring What We Are Made Of

The Physics Teacher 57, 446 (2019); https://doi.org/10.1119/1.5126820

Damped Oscillations with a Smart Cart

The Physics Teacher 57, 490 (2019); https://doi.org/10.1119/1.5126833

The Coming Revolution in Physics Education

The Physics Teacher 57, 493 (2019); https://doi.org/10.1119/1.5126834

\section{A APT Learn about the newest AAPT member benefit}




\section{Using a local posi- tioning system to track 2D motion}

Paul R. DeStefano, Cora Siebert, and Ralf Widenhorn, Department of Physics, Portland State University, Portland, OR

1 racking the motion of an object in $2 \mathrm{D}$ room or as a laboratory activity is difficult to accomplish in real time with traditional equipment used by educators. A local positioning system (LPS), like the Pozyx Creator series LPS, ${ }^{1}$ has a potentially wide range of educational applications for introductory physics courses. In a previous article ${ }^{2}$ we

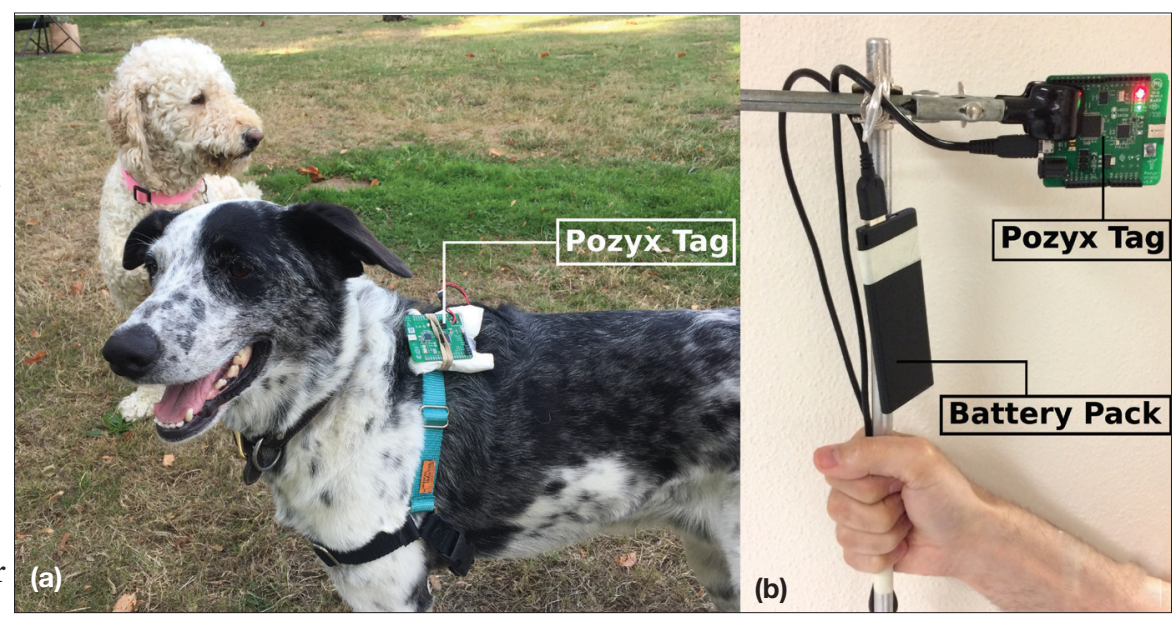

Fig. 1. (a) Pozyx tag, worn by a dog, Elmer. (b) Tag setup for student activities. Battery packs can power the tag for several hours via a USB connector. reported using this product to track one-dimensional motion, pressure, rotation, and magnetic field data, but here we discuss how such systems can provide location information (to within approximately $\pm 10 \mathrm{~cm}$ ) in one, two, and potentially three dimensions both indoors and outdoors.

\section{Overview}

LPS technology allows one to track the motion of any object to which a tag can be attached (Fig. 1). Various combinations of tags and anchors allow for continuous positioning in one to three dimensions (however, we often struggle to achieve good accuracy in three dimensions). In two- or three-dimensional experiments, the tag's coordinates are determined using at least four anchors that act like satellites to perform trilateration similar to the ubiquitous global positioning system, better known by its initials GPS. This connection to GPS may provide for stimulating discussions with students, who are sure to be familiar with the technology's use, but will often lack an understanding of its physical underpinnings. To communicate between devices, the Pozyx LPS uses ultra-wideband (UWB) wireless radio technology, which has the advantage of penetrating thin layers of materials, such as foam or plastic. The algorithm to localize a tag is based on two-way ranging of UWB signals transmitted between the tag and the anchors.

\section{Two-dimensional position graphs}

The ability to track motion in two dimensions can be useful to physics educators in a variety of teaching environments. Below, we present the position data resulting from a test in which we attach the LPS to the collar of the dog of one of the authors and engage the dog in a game of fetch. Next, we plot $y$ vs. $x$-position [Fig. 2(a)] and, separately, the $x$ - and $y$-position as a function of time [Fig. 2(b)]. Since the data rate is roughly constant, the distance between points in Fig. 2(a) indicates the velocity of the dog's movement. This feature is visible when the dog gives chase after the Frisbee and when the dog slows down to catch it. Similarly, the slopes in Fig. 2(b) are steeper as the dog is chasing after the Frisbee and shallower as the dog trots the Frisbee back. Students can calculate average veloci-

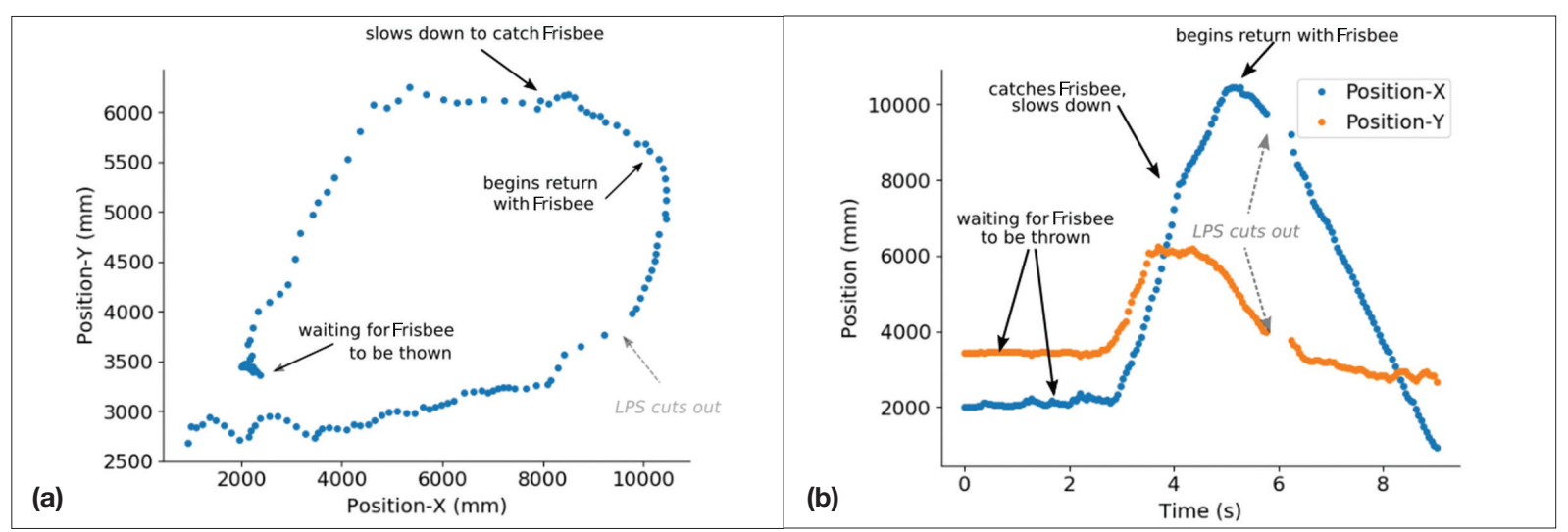

Fig. 2. (a) Two-dimensional position data of the dog Elmer playing fetch. (b) Corresponding $x$ - and $y$-position as a function of time. 


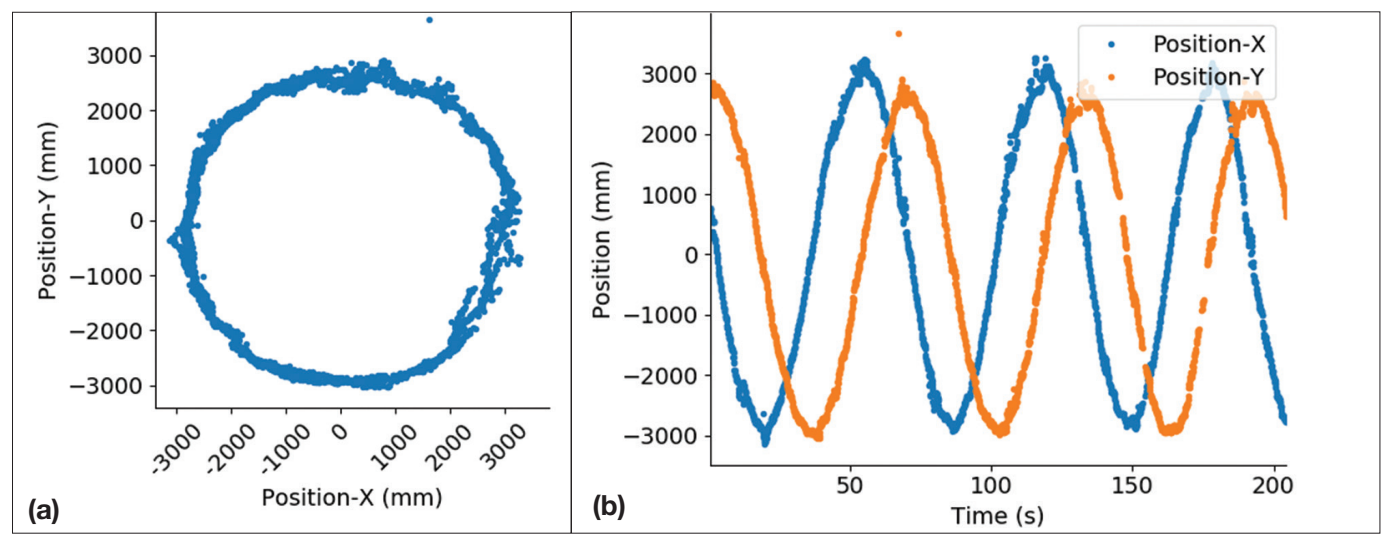

Fig. 3. (a) $x$ - and $y$-position of a tag held by a student slowly walking at a constant speed in a $3 \mathrm{~m}$ radius circle. (b) Corresponding $x$ - and $y$-position plotted as a function of time.

ties from linear fits of the position vs. time data. Note that the alignment of anchors, tags, and obstructions can affect signal reception, occasionally resulting in an interruption (Fig. 2).

An example of how the LPS can be used in a kinesthetic student activity, as is illustrated in Fig. 3, has students engage with the connection of uniform circular motion, sinusoids, and trigonometry. Here, they observe their $x$ - and $y$-position data [see Fig. 3(a)] in real time as they slowly walk at a constant speed in a circle of radius $3 \mathrm{~m}$ while holding the tag as shown in Fig. 1(b). In this case, the student completed three full revolutions resulting in sinusoids for the $x$ - and $y$-position, which are out of phase by $90^{\circ}$, vs. time [Fig. 3(b)]. Further discussions may follow regarding the relations between position, velocity, and speed. The data set in Fig. 3 contains about 2200 data points, which corresponds to an average sample rate of just over $10 \mathrm{~Hz}$. For faster motion, one can set data rates of up to $30 \mathrm{~Hz}$ for two-dimensional positioning of a single tag. The lower rate of this data set is due to the fact that we simultaneously collected the position (not shown) of a second tag. The newer Pozyx Enterprise LPS, which was not employed here, promises higher data rates for multi-tag positioning. ${ }^{1}$

\section{Limitations and further applications}

There are advantages and disadvantages of using an LPS as compared to some instruments currently used in physics instruction. Typical measuring devices include the stopwatch, ultrasonic and infrared range finders, and video-capture technology. While each of these methods tracks motion well, they either have low sampling rates (stopwatch), orientation and range restrictions (range finders), or can be quite time consuming to use (video analysis). The LPS device does not have these shortcomings, but that is not to say it has none of its own. Due to the accuracy of the position data, instantaneous velocities calculated on a point-by-point basis exhibit a large variance. While the data collection process is relatively quick and easy, software needed to be written to achieve this task. At Portland State University, we have developed a tool for this purpose using the Python library provided by the manufacturer and released it under an open source license. ${ }^{3}$

With LPS, the opportunity for teachers to develop engaging alternatives to classic experiments is abundant, as is the creative control that students may have over their experiments. Because of the versatility of these devices, physical questions may be explored from different perspectives for a variety of objects. Local positioning systems are a genuinely unique category of instrument, ${ }^{4}$ they are ready to use at this time, and may find an increasing number of applications in kinematics laboratories as the technology improves further.

\section{References}

1. Pozyx Labs (2018). Pozyx - centimeter positioning for Arduino. Retrieved from https://www.pozyx.io/product-info.

2. Cora Siebert, Paul R. DeStefano and Ralf Widenhorn, “Teaching physics with a local positioning system," Phys. Teach. 57, 428 (Sept. 2019).

3. PSU-Pozyx-GUI-source code (2019), Github repository, https://github.com/psuphysicsedres/PSU-Pozyx-GUI-source.

4. Gabriel Deak, Kevin Curran, and Joan Condell, "A survey of active and passive indoor localisation systems," Comp. Comm. 35, 1939 (2012). 